\title{
Editorial
}

\section{Reflexiones sobre la patología ocular}

\section{Reflexionts on ocular pathology}

J. Cuevas-Álvarez ${ }^{a}$, J. Forteza-Vila ${ }^{a}$, P. Hiscott ${ }^{b}$, R. Proença $^{c}$, M. C. Dinarés-Fernández ${ }^{d}$, L. Alfaro-Ferreres ${ }^{e}$, E. Roselló-Sastre ${ }^{e}$, F. Arce-Mateos ${ }^{f}$, N. Camarasa-Lillo ${ }^{e}$, B. Madrigal-Rubiales ${ }^{9}$, A. López-Esteban $^{h}$, N. Fernández-Alonso ${ }^{i}$, J. M. Pigazo-Merino $^{i}$ y J. C. Pastor-Jimeno ${ }^{i}$

a Universidad de Santiago de Compostela, Santiago de Compostela, España

b Universidad de Liverpool, Reino Unido

c Universidad de Coimbra, Coimbra, Portugal

d Hospital Vall d’Hebron, Barcelona, España

e Hospital Universitario Doctor Peset, Valencia, España

${ }^{\mathrm{f}}$ Hospital Universitario Marqués de Valdecilla, Santander, España

g Hospital Río Hortega, Valladolid, España

$\mathrm{h}_{\text {Hospital La Paz, Madrid, España }}$

${ }^{\mathrm{i}}$ IOBA, Universidad de Valladolid, Valladolid, España

El día 5 de noviembre se celebró en Valladolid la reunión del Club de Patología Ocular, de la Sociedad Española de Anatomía Patológica, que preside el profesor Juan Cuevas Álvarez. En el transcurso de la misma se celebró una reunión de trabajo que elaboró el siguiente documento:

¿Hay algún papel para un patólogo en un centro o estructura de investigación biomédica aplicada en españa? Si es así, ¿cuál puede ser su función?

Se considera que un patólogo puede ser un elemento clave para establecer y/o facilitar una conexión entre los investigadores básicos y clínicos. Puede ayudar a los investigadores básicos a interpretar hallazgos que necesiten base morfológica. Y lo que es muy importante: facilitar su conexión con la clínica.

Resulta destacable su papel en el análisis del impacto de los nuevos tratamientos sobre los tejidos de los pacientes, que constituye un área importante de la investigación biomédica, y puede comprobar las respuestas biológicas a las diferentes terapéuticas. De tal manera que los patólogos pueden ocupar una posición clave en la investigación traslacional.
Su entrenamiento en morfología hace a los patólogos especialmente valiosos en la localización de los problemas en los tejidos. Están legalmente reconocidos para conservar y proporcionar el acceso a los tejidos de origen humano con fines de investigación.

Pueden proporcionar algunas de las plataformas horizontales necesarias en los centros de investigación biomédica aplicada, tales como la morfología, la inmunohistoquímica, la patología molecular y los biobancos.

También pueden desempeñar una importante función en temas de calidad en investigación, como auditores, por ejemplo, determinando la precisión de los nuevos procedimientos diagnósticos en el marco de la clínica, las nuevas clasificaciones de enfermedades y el impacto de los tratamientos.

\section{¿Cómo se puede estimular a los patólogos a desempeñar un papel importante en la investigación traslacional?}

En su origen, los patólogos aportaban principalmente investigación, y prueba de ello es que la primera revista norteamericana 
de Patología se denominó Experimental Medicine. Sin embargo, la evolución del tratamiento del cáncer y las exigencias de la Medicina moderna fomentaron el predominio de la Patología quirúrgica, que antes hacían los cirujanos y posteriormente absorbieron los patólogos, quienes abandonaron, en parte, la investigación.

Es importante reconocer que un patólogo debe ser un investigador principal más del centro y debe poseer su propia línea de investigación; es decir, liderar su propio proyecto y no solo colaborar en los proyectos de otros.

Parece fundamental acercar a los patólogos durante su periodo de residencia. Hay que motivar precozmente a los residentes en Patología a dedicar parte de su trabajo a la investigación y estimular así las vocaciones hacia ella. Este mensaje sobre lo que es la Patología debe hacerse llegar claramente a los estudiantes de Medicina. En este sentido, los tutores y los directores de los departamentos tienen una importante responsabilidad. Un medio para fomentar la investigación en los estudiantes puede ser la de juntar patólogos entrenados con estudiantes de una especialidad concreta, especialmente de una en la que el patólogo esté interesado. Estos equipos pueden trabajar en el desarrollo de proyectos de investigación con un beneficio mutuo.

Hay que mantener reuniones regulares y mutidisciplinares de los patólogos con los otros especialistas clínicos y con los investigadores más básicos, lo que ya se hace en el área de cáncer de forma tradicional. Este tipo de reuniones pueden desempeñar diferentes funciones en el ámbito de la investigación y, por lo tanto, en el reclutamiento de personal interesado en investigar; pueden incluir el refuerzo de los lazos entre clínicos y patólogos y, cuando corresponda, a investigadores más básicos. Es conveniente revisar el impacto de los nuevos tratamientos y asegurarse de que los miembros de un equipo utilizan el mismo lenguaje técnico.

Se necesita cambiar la idea de que cualquier sugerencia de colaborar en un nuevo proyecto de investigación, es simplemente "más trabajo" para el patólogo, motivándolos a hacerlo. Es necesario combatir la idea de que la investigación consume mucho tiempo y no lleva a ninguna parte. Hay que transmitir la idea de que la investigación conduce a la excelencia tanto en la Patología como en la Medicina clínica.

\section{¿Cómo se podría estimular a los patólogos generales a dedicarse a subespecialidades tales como la patología ocular?}

Se considera que en el sistema sanitario actual de muchos países, la especialización es una ventaja, pero que a la vez también puede ser un problema, sobre todo a la hora de desarrollar la actividad en puestos de trabajo en pequeños hospitales. No obstante, en el camino de especialización y subespecializacion de la Medicina clínica, la Histopatología tiende por sí misma a especializarse y en muchos países el concepto histopatólogo general tiende a ser un término del pasado. Además, la Medicina va avanzando cada vez más en el sentido de curar enfermos, y no enfermedades. Y en ese camino hacia la personalización, los patólogos pueden jugar un papel relevante. Hay pues una presión social sobre ellos para que se subespecialicen. En esta situación, el patólogo experto debe apostar por la subespecialización, porque en definitiva es lo mejor para el paciente.
Los patólogos deben ser capaces de dar respuestas adecuadas a las preguntas de los clínicos y para ello deben conocer qué es lo que los clínicos desean. En general, los clínicos desean respuestas y no meras descripciones macro- o microscópicas, lo que exige al patólogo conocer en profundidad las enfermedades.

Es fundamental avanzar en la línea de que el patólogo colabore en proporcionar diagnósticos con alto valor añadido para el enfermo, que faciliten los tratamientos e informen sobre el pronóstico.

Todos estos cambios refuerzan la idea de que es cada vez más difícil que un patólogo general cubra de manera adecuada las demandas de los especialistas clínicos.

Es necesario que los residentes de cualquier especialidad, incluyendo la Oftalmología, dediquen un tiempo de su formación a la Patología ocular, interaccionando con el patólogo para conocer su punto de vista. Este requisito proporciona la oportunidad de poner juntos a residentes de Patología con los de otras especialidades no solo para aprender, sino en la discusión de casos no rutinarios. Para ayudar al patólogo, es fundamental que los clínicos proporcionen de forma detallada toda la información sobre los especímenes de las biopsias. Si el clínico demuestra entusiasmo, el residente de Patología lo detectará y podrá orientar su vocación hacia esa especialidad. El desarrollo de reuniones periódicas puede también contribuir a estimular el interés.

Es interesante crear equipos de patólogos y oftalmólogos con intereses comunes y hacer que el clínico "siga" la biopsia desde la mesa de quirófano hasta el diagnóstico definitivo, pero también puede ser interesante que el patólogo "siga" al paciente y no solo a la biopsia. Es decir, que participe en la emisión del diagnóstico, incluso teniendo una consulta para hablar con el paciente y explicar sus diagnósticos.

En este contexto de cambio de perspectiva, la actitud del jefe de servicio es nuevamente crucial y debe estimular la investigación, la subespecialización y fomentar las interacciones con los clínicos creando la atmósfera adecuada.

Deben estimularse las vocaciones académicas entre los patólogos, para lo que resulta necesario buscar algún tipo de compensación para los profesionales que decidan recorrer este camino.

Se hace también la reflexión de que es posible que para que los patólogos se motiven debe promocionarse la participación de clínicos relevantes en los congresos de Patología.

Es posible que uno de los problemas con la Patología subespecializada sea que el patólogo se encuentra cómodo con el diagnóstico de malignidad/benignidad (surgical pathology) en las lesiones oculares, pero algo inseguro en la Patología inflamatoria y/o degenerativa cuyo conocimiento debería estimularse ya que es de vital importancia para el clínico. El problema puede solventarse mediante la creación de centros de referencia o de segunda opinión, donde los patólogos puedan aumentar sus conocimientos y conseguir ayuda. En este sentido debe apostarse por la telepatología que probablemente desempeñará un papel muy importante. Estos centros deben proporcionar cursos y entrenamiento a los patólogos que deseen especializarse.

Todas estas actividades de formación deben estar apoyadas por las respectivas sociedades científicas que además deben garantizar su calidad docente. 